\section{Alcohol and pregnancy}

In their national survey of post-pregnancy follow-up of women with gestational diabetes mellitus, Pierce and colleagues found a lack of adherence to National Institute for Health and Clinical Excellence (NICE) guidelines.' NICE have recently updated their recommendations of safe alcohol limits in pregnancy, but it is unclear whether people are aware of the new guidelines. Having previously recommended no more than one unit of alcohol per day during pregnancy, ${ }^{2}$ NICE now recommend no more than one or two units a week. ${ }^{3}$ NICE also advise avoiding alcohol completely in the first trimester of pregnancy. ${ }^{3}$ Although recommendations vary, all guidelines emphasise the danger of binge drinking. ${ }^{2}$

In September 2011, we carried out a questionnaire survey of women aged 16 to 40 years to investigate their knowledge of the new guidelines on safe consumption of alcohol during pregnancy. Women sitting in or walking through Leicester Square, London were given a patient information sheet and asked if they were willing to complete a brief, confidential questionnaire on alcohol in pregnancy. The questionnaire asked how many units of alcohol are recommended as safe during pregnancy and in which trimester of pregnancy it is safest to drink.

The response rate in 186 eligible women was $54 \%(100 / 186)$, and their mean age was 23 years, 97 correctly said the recommended level was no more than one or two units a week, of whom 79 thought no alcohol should be consumed during pregnancy. However, three women thought it was safe to drink one or two units daily. All 99 women who responded to the question agreed that it is unsafe to drink five units of alcohol ('binge drinking') at one sitting during pregnancy. However, contrary to the guidelines, a third (32/99) of women thought that drinking was safest in the first trimester.

This survey showed the majority of participants knew the safe alcohol levels recommended during pregnancy in the new NICE guidelines. However, the study did reveal that a third of women incorrectly presumed that it was safer to drink in the first trimester of pregnancy. Perhaps, by increasing awareness, more women will avoid alcohol during this trimester.
However, many pregnancies are unplanned, some may be associated with binge drinking, and women may unwittingly drink in the first 3 months of pregnancy before they know they are pregnant. Pierce and colleagues suggest education of women about the need for follow-up after gestational diabetes mellitus is important. We suggest another role for primary care may be to continue education about safe alcohol limits, especially during the first trimester of pregnancy.

\section{Gloria Jesuratnam,}

Medical Student, St George's Medical School, University of London, SW17 ORE. E-mail: gloria_jahotmail.co.uk

Pippa Oakeshott,

Reader in General Practice, St George's Medical School, University of London.

\section{Raja Mukherjee,}

Consultant Psychiatrist for people with $L D$ (Tandridge), Lead Clinician Specialist FASD Behaviour Clinic, St George's Medical School, University of London.

\section{Acknowledgment}

We thank all the participants and Dr Sedgwick.

\section{REFERENCES}

1. Pierce M, Modder J, Mortagy I, et al. Missed opportunities for diabetes prevention: postpregnancy follow up of women with gestational diabetes mellitus in England. Br J Gen Pract 2011; DOI: 10.3399/bjgp11X6013116.

2. British Medical Association Board of Science. Foetal alcohol spectrum disorders - a guide for healthcare professionals. London: British Medical Association Board of Science, 2007. http://www.bma.org.uk/images/FetalAlcoholSpect rumDisorders_tcm41-158035.pdf laccessed 8 Nov 2011).

3. National Institute for Health and Clinical Science. Antenatal care, routine care for the healthy pregnant woman. NICE, 2008: 95 http://www.nice.org.uk/nicemedia/live/11947/4014 5/40145.pdf (accessed 8 Nov 2011)

DOI: 10.3399/bjgp11X613025

\section{The Olympic legacy}

It was with surprise that I read Mike's Fitzpatrick's assertion that exercise is 'deemed virtuous but has no proven value in relation to health.' Skimming through over 40 references in the Department of Health Lets Get Moving commissioning guidance ${ }^{2}$ made me feel that Mike needs to spell out the reasoning for his claim a little more robustly.

Rachel Pryke,

GP, Winyates Health Centre, Redditch,

Worcestershire, B98 ONR.

E-mail: rachelgprykelabtinternet.com

\section{REFERENCES}

1. Fitzpatrick M. The Olympic legacy. Br J Gen Pract 2011; 61(592): 688

2. Foster J, Thompson K, Harkin J. Let's get moving - a new physical activity care pathway for the NHS. London: NHS, 2009.

http://www.theleisurereview.co.uk/articles11/Lets GetMovingSept09.pdf (accessed 9 Nov 2011).

\section{Physical inactivity is associated with earlier mortality - the evidence is incontrovertible}

We commend BJGP for publishing and bringing much needed attention to the opinions of Mike Fitzpatrick on the perceptions of physical activity promotion within the healthcare sector in this country.

There is, however, nothing virtuous, propagandist, patronising, and infantile about physical inactivity being the fourth leading risk factor for global mortality responsible for $6 \%$ of worldwide deaths and a major contributing factor to $60 \%$ of global non-communicable diseases. ${ }^{2}$ There is a clear causal relationship between the amount of movement people do and allcause mortality. ${ }^{3}$

Behaviour change psychology permeates all aspects of medicine and it is interesting to note that, despite widespread acceptance of pharmaceutical medications by doctors, enormous pharmaceutical advertising expenditure, and a large proportion of medical education being devoted to pharmacology, only $30-50 \%$ of patients change their behaviour sufficiently to consume prescribed medication at advised therapeutic doses. ${ }^{4}$ Changes to medical education are urgently needed to include greater emphasis on behaviour change techniques for they underpin much of what we do in clinical practice, and are effectively used to modify physical inactivity behaviour 
in primary care. ${ }^{5,6}$

Dr Fitzpatrick insinuates that coordinated public health strategies involving health professionals and physical activity promotion have "no proven value in relation to health'. We congratulate Fitzpatrick on promoting lifestyle promotion at his clinic, according to the NHS Information Centre, last year his own surgery achieved 100\% incentivised payments from QOF for lifestyle promotion indicators. Brief interventions in primary care achieve similar concordance with physical activity to prescribed medication, ${ }^{7.8}$ so lifestyle recommendations are in fact of very great value in relation to health with far wider collateral benefits. $9.10,11$

Physical activity promotion and lifestyle advice are included as the first treatment recommendation in 39 different sets of clinical guidelines in the UK because evidence supports that physical activity can be used to treat the same diseases that physical inactivity causes land improve quality of life, mental health, productivity, and academic achievement). ${ }^{12}$

Medical ethics, medico-legal duties of care, and perhaps even moral responsibility also underpin the need for physical activity promotion, to the extent that General Medical Council Good Medical Practice obligations, state that You should encourage patients and the public to take an interest in their health and to take action to improve and maintain it. This may include advising patients on the effects of their life choices on their health and wellbeing .....$^{13}$

As a start, some simple tips assisting doctors with physical activity promotion in primary care was recently published in the $B M J .^{14}$

\section{Richard Weiler,}

Honorary Consultant in Sport and Exercise Medicine, University College London Hospitals NHS Foundation Trust, 235 Euston Road, London, NW1 2BU.

E-mail: rweilerladoctors.org.uk

\section{Emmanuel Stamatakis,}

Senior Research Associate/NIHR Career Development Fellow, University College London, Research Department of Epidemiology and Public Health, London.

\section{Steven N Blair,}

Professor, Faculty Affiliate, Division of Health Aspects of Physical Activity/EPID, University of South Carolina, Department of Exercise Science, Columbia, South Carolina, US.

\section{REFERENCES}

1. Fitzpatrick M. The Olympic legacy. Br J Gen Pract 2011; 61(592): 688

2. World Health Organization. Global recommendations on physical activity for health Geneva: WHO, 2010

http://www.who.int/dietphysicalactivity/strategy/eb 11344/strategy_english_web.pdf laccessed 8 Nov 2011).

3. Department of Health. Start active, stay active. A report on physical activity for health from the four home countries.' London: DoH, 2011

http://www.dh.gov.uk/dr_consum_dh/groups/dh_ digitalassets/documents/digitalasset/dh_128210.p df laccessed 8 Nov 2011).

4. McDonald HP, Garg AX, Haynes RB. Interventions to enhance patient adherence to medication prescriptions: scientific review. JAMA 2002; 288(22): 2868-2879

5. Writing Group for the Activity Counseling Trial Research Group. Effects of physical activity counseling in primary care: the Activity Counseling Trial: a randomized controlled trial. JAMA 2001; 286(6): 677-687.

6. Michie SM, Ashford S, Sniehotta FF, et al. A refined taxonomy of behaviour change techniques to help people change their physical activity and healthy eating behaviours: The CALO-RE taxonomy. Psychol Health, 2011. [Epub ahead of print]

7. Lawton BA, Rose SB, Raina Elley C, et al Exercise on prescription for women aged 40-74 recruited through primary care: two year randomised controlled trial. Br J Sports Med 2009; 43(2): 120-123

8. Weiler R, Stamatakis E. Physical activity in the UK: a unique crossroad? Br J Sports Med 2010; 44(13): 912-914.

9. Umpierre D, Ribeiro PA, Kramer CK, et al. Physical activity advice only or structured exercise training and association with $\mathrm{HbA1c}$ levels in type 2 diabetes: a systematic review and metaanalysis. JAMA 2011; 305(17): 1790-1799.

10. Lindström J, Ilanne-Parikka P, Peltonen M, et al. Sustained reduction in the incidence of type 2 diabetes by lifestyle intervention: follow-up of the Finnish Diabetes Prevention Study. Lancet 2006; 368(9548): 1673-1679.

11. Church TS, Blair SN, Cocreham S, et al. Effects of aerobic and resistance training on hemoglobin A1c levels in patients with type 2 diabetes: a randomized controlled trial. JAMA 2010; 304(20): 2253-2262.

12. Weiler R, Feldschreiber P, Stamatakis E. Medicolegal neglect? The case for physical activity promotion and exercise medicine. Br J Sports Med 2011. [Epub ahead of print].

13. General Medical Council. Good medical practice. GMC, 2006. http://www.gmc-

uk.org/guidance/good_medical_practice.asp laccessed 8 Nov 2011).

14. Khan KM, Weiler R, Blair SN. Prescribing exercise in primary care. BMJ 2011; 343: d4141.

DOI: 10.3399/bjgp11X613061

\section{Time for a national undergraduate curriculum for primary care}

Blythe and Hancock pose an interesting question, but their article does not highlight three important issues. ${ }^{1}$ First, that an undergraduate curriculum results in a generic 'product', whose nascent knowledge and competency must relate to patient care regardless of their subsequent specialisation. Second, that these competencies will be attained in different ways in different settings, and often are and should be practised in more than one undergraduate setting or speciality, both prescribing and consultation skills are exemplars. Third, the fact that a specific speciality does or does not lead on a specific component may not mean that the graduate fails to achieve that competency. So, let's pretend that medical school (a) makes prescribing tasks a core learning activity of its final year GP placement, but medical school (b) signs off this competency at the end of year 4 in the medicine for the elderly placement, and uses its final year GP placement to focus on the applied skills of acute diagnosis of undifferentiated problems. From the primary care curriculum in each school this will look different, but both sets of graduates should be able to succeed in relevant work-based and objective structured clinical examination' type assessments.

The idea in this article, therefore, needs further refinement to ensure it will provide useful information that will act as a driver for relevant change, as trying to map entry competencies for MRCGP onto GP departmental teaching alone would not reflect such legitimate variation. A national comparative mapping of current use of primary care placements, ${ }^{2}$ and the learning objectives they prioritise, might well be more informative, particularly because there are clear differences in long-term career impacts that may relate to the nature and status of GP-teachers in different UK medical schools. ${ }^{3}$ Links between GP teaching leads at different medical schools are actually already established in the Society for Academic Primary Care's 'Heads of Teaching' network, and the Royal College of General Practitioners is, and will remain, a champion of exposing medical students and postgraduates to our discipline. Giving 